\title{
DISCURSO E MEMÓRIA DA(S) IDENTIDADE(S) EM CRISE: EFEITOS IDENTITÁRIOS EM CHARGES ONLINE SOBRE SUJEITOS PROFESSORES
}

\author{
Discourse and memory of identity(s) in crisis: \\ identity effects in online cartoons on teacher subjects
}

\author{
Daléxon Sérgio da SILVA \\ Universidade Católica de Pernambuco \\ dalexon@uol.com.br \\ http://orcid.org/0000-0002-5977-361X \\ Éderson Luís SILVEIRA \\ Universidade Federal de Santa Catarina \\ ediliteratus@gmail.com \\ http://orcid.org/0000-0002-8483-4656
}

\begin{abstract}
RESUMO: No presente texto, a partir de um gesto de leitura e de interpretação, objetivamos analisar três charges que apresentam um discurso acerca da identidade do professor, que tem circulado na atualidade através de uma relação constitutiva, na historicidade, cujo acionamento se dá por meio da memória discursiva. Diante disso, buscamos apresentar uma visão teórica e analítica sobre esta circulação, baseados na Análise de Discurso de linha francesa, fundamentada nos estudos de Pêcheux (1969) e Orlandi (2001) no Brasil, numa interface com os Estudos Culturais, respaldados em Bauman (2005), Hall (2001) e
\end{abstract} Silva (2003).

PALAVRAS-CHAVE: Discurso; Sujeito; Memória Discursiva; Identidade.

\begin{abstract}
In the present paper, based on a gesture of reading and interpretation, we aim to analyze three cartoons that present a discourse about the identity of the teacher, which has circulated nowadays through a constitutive relationship, in historicity, whose activation occurs through discursive memory. Therefore, we seek to present a theoretical and analytical view on this circulation, based on the Discourse Analysis of the French line, based on the studies of Pêcheux (1969) and Orlandi (2001) in Brazil, in an interface with cultural studies, supported by Bauman (2005), Hall (2001) and Silva (2003).

KEYWORDS: Discourse; Subject; Discursive Memory; Identity.
\end{abstract}




\section{EFEITO DE INÍCIO}

Como o presente texto parte de uma análise acerca de identidades e formas de identificação subjetivas relacionadas a sujeitos docentes para então efetuar uma distinção necessária - tais identidades estão sendo perpassadas por uma crise - é preciso, antes, apresentar o que estamos considerando teoricamente em alusão ao conceito de identidade. Para o sociólogo e filósofo polonês Bauman (2005), a identidade se revela como invenção e não descoberta; é um esforço, um objetivo, uma construção ininterrupta. Trata-se, portanto, de algo inconcluso, inacabado. Neste âmbito, refletir sobre ter uma identidade não ocorre no sentido de haver um pertencimento, mas quando se pensa em uma atividade passível de reelaboração, heterogênea e heteroclitamente orientada.

Esse enfoque surge da crise do pertencimento, sustentada na premissa de soberania do sujeito no bojo das Ciências Humanas, reforçada pelo cartesianismo. Desse modo, para o referido autor, a essência da identidade constrói-se em referência aos vínculos que conectam os sujeitos uns aos outros, considerando-se esses vínculos estáveis e marcados, também, pela instabilidade que constitui possibilidades de vir-a-ser. Logo, o habitat da identidade é um campo de batalha: ela só se apresenta no tumulto. Não se pode evitar sua ambivalência: ela é uma luta contra a dissolução e a fragmentação, uma intenção de devorar e uma recusa a ser devorada, assim, essa batalha a um só tempo une e divide como inclusão e segregação, misturando-se e complementando-se. Não é à toa que ele entende a identidade como mutação permanente.

De uma perspectiva semelhante à de Bauman (2005), a partir de um direcionamento específico que perpassa questões relacionadas à identidade cultural, Stuart Hall (2001), teórico cultural jamaicano que atuou no Reino Unido, apresenta um conceito que denomina como "identidades culturais", associado a aspectos de nossas identidades que surgem de nosso "pertencimento" a culturas étnicas, raciais, linguísticas, religiosas e, também, nacionais. O autor entende que as condições atuais da sociedade estão "fragmentando as paisagens culturais de classe, gênero, sexualidade, etnia, raça e nacionalidade que, no passado, nos tinham fornecido sólidas localizações sociais" (HALL, 2001, p. 9).

No presente trabalho a questão da identidade é um elo nodal das discussões empreendidas. Ao observarmos diversos tipos de charges pode ser percebida a presença de 
uma regularidade a partir da aparição de memórias discursivas acerca da identidade do professor que embora ressignificadas aproximam-se a partir dessa regularidade. Nossa atenção se volta para o âmbito da docência porque, com o passar do tempo, as transformações no mundo do trabalho, o avanço tecnológico e a proliferação do alcance dos meios de informação têm exercido cada vez mais efeitos sobre as instituições educacionais. Tais mudanças fazem com que a escola seja atingida no escopo de concepções e formas de construção do saber, concatenando-se à problematização do fazer docente. Já faz algum tempo que observamos, na história dos processos educativos, que há um conjunto de novas demandas que pressionam os professores a redefinirem seus papéis e tarefas, contribuindo para o surgimento de novas identidades.

As charges estão associadas a determinadas práticas sociais situadas em determinado período histórico e apontam para uma inscrição que é histórica, cultural e ideologicamente orientada desde sua constituição, apontando para um recorte da vida social a partir de um direcionamento específico. De acordo com Torres (2001), essas práticas são marcadas pelas formas como os sujeitos as representam socialmente; no caso das charges analisadas neste trabalho veremos que a escola e os professores têm um papel fundamental na construção dessas práticas.

Faz algum tempo que se considera a questão da docência como uma profissão sobre a qual recaem necessidades de transformações a fim de se adequar às demandas do ensino e de formação da sociedade. Ao docente muito é cobrado. No entanto, raras são as instâncias em que tais cobranças implicam na valorização da categoria. Não é à toa que a falta de remuneração adequada é um dos maiores empecilhos e desafios da educação brasileira ao longo da história. Pensando que a identidade tem a ver com discursos, práticas e representações que vão se inscrevendo na memória sobre determinados sujeitos, a desvalorização docente também é parte deste aglomerado de processos de identificação acerca do que viria a ser o sujeito professor.

A remuneração insuficiente ou a precarização do trabalho docente ocorre em meio a um regime que, frequentemente, se apresenta sob as vestes da democracia, embora, na prática, o Brasil tenha aparição questionável no âmbito de rankings mundiais de regimes democráticos ${ }^{1}$. Diante disso, vale situar que o termo democracia enquanto sistema político

1 Em rankings mundiais de democracia, o Brasil aparece em má situação, disponível em: 
tem origem na Grécia, em meio a um contexto aristocrático. A expressão democracia deriva do léxico demo, que significa povo, e kracia, que remete a governo. Seria, portanto, um governo do povo (AZAMBUJA, 1998). Considerando-se que a noção de democracia, que implica num conceito de cidadania democrática responsável e que práticas democráticas, além de políticas, são também pedagógicas, pode-se projetar os riscos que corre a democracia com o descrédito da figura do professor e o desmantelamento dos sistemas de ensino e, também, pode ser problematizada a existência de práticas antidemocráticas no âmbito de um sistema democrático (COSTA; SILVEIRA, 2018).

A Análise do Discurso de linha francesa ${ }^{2}$, centrada nos estudos de Pêcheux (1969), na Europa e Orlandi (2001) no Brasil, nos traz elementos teóricos e analíticos pertinentes em relação à identidade do sujeito docente analisada nesta pesquisa, ao papel da memória e ao discurso, considerado em suas condições de produção. Numa interface com os Estudos Culturais, tomados a partir de Stuart Hall, Tomaz Tadeu da Silva e Zygmunt Bauman, por exemplo, serão pensadas questões relacionadas às identidades culturais, aos modos de identificação dos sujeitos e questões adjacentes.

Ao observar tais aspectos demonstrados, algumas questões se fizeram presentes: busca-se investigar como o discurso acerca da identidade do professor, nas charges analisadas, produz efeitos de sentido, que efeitos são produzidos a partir da similaridade entre elas, e como se dá a questão da memória discursiva e se ocorre a materialização de um já-dito, cristalizado, nas charges.

A partir destes questionamentos norteadores de análise buscaremos situar, então, as questões teóricas nas páginas seguintes até culminar na análise discursiva propriamente dita para, então, rumar para um efeito de fechamento.

\section{A ANÁLISE DE DISCURSO DE LINHA FRANCESA}

É em meados dos anos 60 e 70 que afloram na França importantes discussões aprofundadas e rupturas em torno do Materialismo Histórico de Althusser, da Linguística Estrutural de Saussure e da Psicanálise, com a releitura lacaniana de Freud.

É nesse direcionamento que a $\mathrm{AD}$ se apresenta como uma desdisciplina, pois se

$<\underline{\text { htps: } / / \text { www.eiu.com/topic/democracy-index }>\text {. }}$

$2 \mathrm{AD}$ daqui em diante. 
instaura a partir da articulação no entremeio de três regiões do conhecimento científico: o Materialismo Histórico, a Linguística e a Psicanálise. Orlandi (2007) a alcunha assim para substituir o termo interdisciplinaridade. A autora recusa essa noção, levando-se em consideração que uma disciplina precisa ser dominante em relação à outra para que a interdisciplinaridade se estabeleça, o que não se configura na análise do discurso de linha francesa, na qual as três teorias em pauta a constituem, de forma paritária. Logo, a AD é de entremeio porque se move no espaço entre a linguística e as ciências das formações sociais, trabalhando conceitos exteriores ao domínio da Linguística. Ela interroga essas três regiões pelo que não consideram. Nesse ponto,

[...] interroga a linguística pela historicidade que ela deixa de lado, questiona o Materialismo perguntando pelo simbólico e se demarca da Psicanálise pelo modo como trabalha a ideologia como materialmente relacionada ao inconsciente sem ser absorvida por ele (ORLANDI, 2007, p. 20).

Nesse aspecto, embora tenha a Linguística em sua veia embrionária, dela se afasta por estar filiada a outras regiões do conhecimento. Ela pressupõe a Linguística, pois compreende a língua como um sistema significante. Para Orlandi (2007) não podemos não estar sujeitos à Linguística, isto é, aos seus equívocos, à sua opacidade, pois não existe neutralidade nem no uso mais cotidiano do símbolo. A autora compreende o discurso como o movimento dos sentidos, enquanto lugares provisórios de conjunção e dispersão, de unidade e de diversidade, de indistinção, incerteza, de hábitos, de ancoragem e de vestígios.

Segundo Orlandi (2007), tal campo de estudos observa a linguagem a partir da concepção de que língua é ideologia e tal atributo a faz significar muitas coisas diferentes. Nesse item, a língua é vista pela $\mathrm{AD}$ como uma mediação necessária entre o homem e a realidade natural e social sendo o discurso o lugar de materialização da língua. Deste modo, sendo o discurso a materialidade específica da ideologia e a materialidade do discurso é a língua, constitui-se, então, uma tríade língua-discurso-história. Nesse ponto, o que a $\mathrm{AD}$ tenta compreender é como se produz o trabalho simbólico e ideológico na língua, fazendo com que nela se produzam sentidos.

Nesse ponto, é proveniente da Psicanálise a contribuição para que se perceba o 
deslocamento que ocorre da noção de indivíduo para a de sujeito, constituída na historicidade, na relação com o simbólico. Pêcheux (1969) compreende que não há discurso sem sujeito nem há sujeito sem o atravessamento da ideologia e é assim que a língua faz sentido. Esse sujeito discursivo funciona pelo inconsciente e pela ideologia, pois ele é descentrado e afetado pelo real da história, não podendo controlar o modo como ela o afeta. Para Pêcheux (1969), o discurso é o efeito de sentidos entre locutores, é estrutura e acontecimento.

A AD está vinculada a três regiões específicas: a Linguística, o Materialismo Histórico e a Psicanálise. Silva, Fátima e Silveira (2020) pontuam que é importante mencionar que tal disciplina extrapola o lugar de existência de mais um campo do saber sendo, também, um projeto de intervenção político-social. Isso porque, de acordo com o Pêcheux (1988, p. 24), sendo um instrumento de luta política, a proposta é "contribuir para o avanço dos estudos na perspectiva do materialismo histórico, do efeito das relações de classe sobre o que se pode chamas as práticas linguísticas". Dessa maneira, a AD compreende, por meio das contribuições da Psicanálise e do Materialismo Histórico, o sujeito como sendo atravessado tanto pela ideologia quanto pelo inconsciente; seu sujeito não é uno ou do cogito, da razão, mas é considerado um sujeito descentrado, cindido, clivado. Ele não se constitui enquanto fonte e origem dos enunciados, pois os processos enunciativos são determinados pela formação discursiva na qual o sujeito falante se inscreve, embora esse sujeito possua a ilusão de ser a fonte ou origem do seu discurso, como bem definiu o autor ao falar dos esquecimentos número um e dois. Sobre a questão da linguagem é importante mencionar, conforme reiteram Piovesan et al. (2006), que, na $\mathrm{AD}$, a linguagem está materializada "na ideologia e a ideologia se manifesta na língua, pois não há discurso sem sujeito, sujeito sem ideologia, nem sujeitos e sentidos estão completos. O discurso é o lugar possível no qual se observa esta relação entre língua e ideologia" (PIOVESAN et al., 2006, p. 4).

Vale, então, mencionar que a $\mathrm{AD}$ entende o sujeito, a linguagem e os sentidos como partes de um todo interacional e indissociável. Seu sujeito é clivado porque é dividido entre o "eu" e "o outro" e, nisso, o discurso se configura como a relação entre sujeitos e sentidos entendidos como aquilo que insere o linguístico em articulação com a história e com a ideologia. Nesse trâmite, a AD concebe a linguagem como um lugar de 
conflito e opacidade que, com a conjunção da história, constitui, por sua vez, um sujeito descentrado, dividido, incompleto.

\section{O PAPEL DA MEMÓRIA DISCURSIVA}

Para a construção do discurso, o sujeito dependerá, constitutivamente, de suas condições de produção, levando-se em consideração que o que garante a especificidade da $\mathrm{AD}$ é a relação que o analista estabelece entre o discurso e a as condições de produção. Orlandi (2005) salienta que as condições de produção compreendem fundamentalmente o sujeito e a situação. Também a memória faz parte da produção do discurso. Para Leandro Ferreira (2001), "há uma memória inerente à linguagem e os processos discursivos são responsáveis por fazer emergir o que, em uma memória coletiva, é característico de um determinado processo histórico".

É nesse ponto que o sentido não existe em si. Ele é determinado pelas posições ideológicas em que as palavras são produzidas. Assim, vale destacar que, no âmbito da $\mathrm{AD}$, as palavras mudam de sentido de acordo com as posições dos sujeitos que as empregam. Nesse enfoque, a linguagem possibilita o aparecimento de deslocamentos em condições de produção específicas. No entanto, pela natureza incompleta do sujeito, dos sentidos, da linguagem, não há garantia de uma determinada produção de sentidos, ou da geração de um deslocamento específico (ou mesmo de qualquer deslocamento) nessa produção.

Nesse direcionamento, o papel da memória discursiva é constitutivo na produção do discurso. Assim, discursivamente orientado, este trabalho assume o conceito de memória discursiva defendido por Pêcheux, ao salientar que:

[...] a memória discursiva seria aquilo que, face a um texto que surge como acontecimento a ser lido, vem restabelecer os 'implícitos' (quer dizer, mais tecnicamente, os pré-construídos, elementos citados e relatados, discursos-transversos, etc.) de que sua leitura necessita: a condição do legível em relação ao próprio legível (PÊCHEUX, 1999, p.52).

Isso posto, para Pêcheux (1999) todo discurso se constitui a partir de uma memória e do esquecimento. Nesse item, os sentidos vão se construindo no embate com outros 
sentidos. Assim, quando não conseguimos recuperar a memória que sustenta aquele sentido, temos o nonsense. Ainda que o falante não tome consciência desse movimento discursivo, ele flui naturalmente. Assim, a memória é o saber discursivo, o já-dito, os sentidos a que já não temos mais acesso, que foram constituídos ao longo de uma história e que estão em nós, sem pedir licença. Orlandi (2001) afirma que o sujeito toma como suas palavras de uma voz anônima que se produz no interdiscurso. Desse modo, há uma apropriação da memória que se manifestará de inúmeras formas por meio de discursos distintos.

Para Mariani (1996), a memória discursiva faz parte de um processo histórico que resulta de uma disputa de interpretações para acontecimentos presentes ou já ocorridos. Courtine e Haroche (1994) chegam a afirmar que a linguagem é o tecido da memória. De outro modo, é um saber que possibilita que nossas palavras façam sentido. Esse saber corresponde a algo falado anteriormente, em outro lugar, a algo "já dito", entretanto, ainda continua alinhavando os nossos discursos. Em razão disso, a memória e, consequentemente, o interdiscurso são responsáveis diretos pela constituição do sentido, como bem atenta Orlandi (2001, p. 33): “a constituição determina a formulação, levandose em consideração que só se pode dizer (formular), colocando-se na perspectiva do dizível (memória, interdiscurso)".

Acerca disso, Pêcheux (1983) esclarece que a memória deve ser entendida como estando situada no entrelaçamento de sentidos da memória mítica, da memória social inscrita em práticas, e da memória do historiador. Para ele, a AD propõe uma posição enunciativa que é, também, aquela de um sujeito histórico, pois seu discurso, uma vez produzido, é objeto de retomada, que se esforça por estabelecer um deslocamento suplementar em relação ao modelo. Assim, a memória suposta pelo discurso é sempre reconstruída na enunciação. Como, por exemplo, neste presente trabalho, conforme se pode observar, nas análises, quando a posição-sujeito de professor é mostrada, a produção deste discurso sempre remete a uma memória social relacionada aos discursos já circulados acerca da posição-sujeito de professor. Assim, os dizeres estão disponíveis, não no próprio sujeito, mas no outro, na memória discursiva.

Assim, o fato de que exista o outro interno em toda memória é a marca do real histórico como remissão necessária ao outro exterior, isto é, ao real histórico como causa 
do fato de que nenhuma memória pode ser um frasco sem exterior. Contudo, para Pêcheux (1999) a memória é muito mais do que uma colagem, uma montagem, uma reciclagem, uma junção. Ela é tudo que pode deixar marcas dos tempos desajustados que nós vivemos e que nos permite a todo o momento, fazer surgir e reunir as temporalidades passadas, presentes e que estão por vir.

\title{
O CONCEITO DE IDENTIDADE NOS ESTUDOS CULTURAIS E A AD: ENTRELAÇAMENTOS POSSÍVEIS
}

Por ser uma "disciplina de entremeio", conforme mencionado por Orlandi (2005), a $\mathrm{AD}$ estabelece o diálogo com outras áreas. Logo, para discutirmos questões concernentes ao sujeito, ao discurso e à identidade, é possível trafegarmos acompanhados dos Estudos Culturais. De acordo com Silva (2003), a identidade se constitui pela diferença, sendo esta, pois, a condição de existência daquela. A identidade e a diferença são, portanto, produtos sociais, que são "fabricados" pela/na linguagem.

Neste aspecto, ele ainda acrescenta:

\begin{abstract}
A identidade e a diferença não podem ser compreendidas, pois, fora dos sistemas de significação nos quais adquirem sentido. Não são seres da natureza, mas da cultura e dos sistemas simbólicos que a compõem. [...] Somos nós que as fabricamos no contexto de relações culturais e sociais. (SILVA, 2003, p. 76-78).
\end{abstract}

É neste aporte que Hall (1997) afirma que a identidade "é definida historicamente, e não biologicamente." a identidade é uma "celebração móvel": formada e transformada continuamente em relação às formas pelas quais somos representados ou interpelados nos sistemas culturais que nos rodeiam, isto é, as identidades são posicionamentos que assumimos, pois são históricas, materializadas em circunstâncias e experiências vividas. Para pensar acerca das construções identitárias, Silva (2003), Santos (2011) e Silveira e Duarte (2012) defendem que ao invés da (des)construção da identidade o que há são processos de identificação e desidentificação. Tal afirmação aponta para a necessidade de problematizar a antropologização do conceito de identidade.

Vale também destacar que a mutação e a fluidez das transformações culturais, de acordo com Bauman (2005) foi fazendo com que o conceito de identidade fosse sendo 
desarticulado de uma noção de unidade para ser pensado sob o signo da multiplicidade constitutiva. Não é a toa que nem a cultura nem a identidade podem ser pensadas como organismos estáticos, permanentes ou passíveis de inércia já que não permanecem os mesmos. As implicações são inúmeras, mas, principalmente, pensar a identidade e a cultura sob o viés do Uno e do Mesmo

[...] não daria conta de explicar os fenômenos que se constroem no mundo sociocultural marcado pela dinamicidade das construções simbólicas fluidas [...] que marcam simbolicamente a identidade e delimitam poder de inclusão ou exclusão (SANTOS, 2011, p. 145).

No caso deste artigo, considerar a análise das condições de produção dos sentidos, que emergem das discursivizações de enunciados contemporâneos oriundos de charges, pode fazer com que seja problematizada a formação da identidade cultural do sujeito professor na contemporaneidade.Assim, pode ser mencionado que culturalmente o sujeito é interpelado em seu fazer histórico-social e a identidade é construída e cambiante, de acordo com Hall (2000, p. 108): “as identidades [...] não são, nunca, singulares, mas multiplamente construídas ao longo de discursos, práticas e posições que podem se cruzar ou ser antagônicos". Sobre a pertinência das discussões no entorno da relação entre os estudos culturais e os estudos discursivos pecheutianos, Silveira e Duarte (2012) mencionam que:

\footnotetext{
Deste modo, no âmbito dos estudos culturais, visto como objeto da cultura, a noção de identidade não tem esse sentido de único, idêntico, igual e permanente. Ao contrário disso, é visto como contraditório, mutável e múltiplo. A partir dos pressupostos da $\mathrm{AD}$ e dos Estudos Culturais, principalmente os que teorizam a respeito da (des) construção de identidade(s), [...] [pode ser observada] a relação entre os efeitos de sentido e os discursos outros que atravessam a produção desses efeitos, sejam construídos nos enunciados ou apagados na construção dos mesmos, para saber o quanto dizem sobre quem representam e sobre quem se direcionam, a partir dos discursos que fazem (res) surgir e/ou apagar (SILVEIRA; DUARTE, 2012, p. 145-146).
}

Considerando a noção de identidade como sendo heterogênea e marcada por transformações, da ordem do contraditório, múltiplo e mutável, e a noção de posiçãosujeito, marcada pela historicidade, pode ser mencionado que se trata, portanto, de uma 
articulação possível entre a AD e os Estudos Culturais. Mais especificamente, podemos ainda afirmar que, articulando com a $\mathrm{AD}$, não são as (in) formações individuais que fazem o sujeito ser ou sentir-se professor, mas sua posição marcada pela historicidade denunciada a partir de uma memória discursiva, presentes nas condições de produção deste discurso circulado na mídia como sua identidade presente nas charges atuais, objeto de estudo deste artigo.

Mas também é preciso falar na distinção conceptual entre os termos sujeito e identidade. $\mathrm{Na} \mathrm{AD}$ é importante discernir identidade de sujeito. Isso porque Pêcheux inicia sua abordagem conceptual sobre o sujeito considerando o âmbito do funcionamento da ideologia e tomando a interpelação como o que torna tangível a relação entre Aparelhos Ideológicos de Estado (AIEs) e os Aparelhos Repressivos do Estado (AREs). Assim, os AREs e os AIEs trabalham a ilusão da identidade, ao passo que a interpelação é aquilo que assujeita em massas de "professores", "lixeiros", "advogados", "diretores", etc. Por que é importante mencionar isso? Porque é assim que se dá a passagem do indivíduo para o sujeito no âmbito da $\mathrm{AD}$. Assim, a interpelação ideológica do indivíduo em sujeito é um apagamento de um hiato “[...] que reside o âmago da relação discrepante indivíduo/sujeito, interpelando (demandando ao indivíduo) uma identidade que faz o sujeito se diluir no indivíduo" (ALMEIDA, 2018, p. 153) como se este fosse "único, insubstituível e idêntico a si mesmo" (PÊCHEUX, 1988, p. 141). Sobre a questão da identidade, é necessário mencionar que não há identidade sem sujeito assim como, também, não há sujeito sem discurso. Assim, a interpelação do indivíduo em sujeito é um dos focos centrais da AD.

Nos Estudos culturais não se fala em interpelação do indivíduo em sujeito, mas na relação entre subjetividade e identidade. Kathryn Woodward (2000) é incisiva ao operar uma distinção entre os termos:

Os termos "identidade" e "subjetividade" são, às vezes, utilizados de forma intercambiável. Existe, na verdade, uma considerável sobreposição entre os dois. Subjetividade sugere uma compreensão que temos sobre o nosso eu. $\mathrm{O}$ termo envolve os pensamentos e as emoções conscientes e inconscientes que constituem nossas concepções sobre "quem somos nós". A subjetividade envolve nossos sentimentos e pensamentos mais pessoais. Entretanto, nós vivemos a nossa subjetividade em um contexto social no qual a linguagem e a cultura dão significado à experiência que temos de nós mesmos e no qual nós adotamos uma identidade. Quaisquer que sejam os conjuntos de 
significados construídos pelos discursos, eles só podem ser eficazes se nos recrutam como sujeitos. Os sujeitos são, assim, sujeitados ao discurso e devem, eles próprios, assumi-los como indivíduos que se posicionam a si próprios. As posições que assumimos e com as quais nos identificamos constituem nossas identidades. A subjetividade inclui as dimensões inconscientes do eu, o que implica a existência de contradições [...]. O conceito de subjetividade permite uma exploração dos sentimentos que estão envolvidos no processo de produção da identidade e do investimento pessoal que fazemos em posições específicas de identidade (WOODWARD, 2000, p. 55-56).

Assim, se pensando a interpelação - e as implicações de tal teorização no escopo da AD - é possível falar em processos de identificação e de desidentificação e, também, de processos de construção de identidades, nos Estudos Culturais, quando o sujeito deixa de ser pensado como uma entidade una e fixa, passa a ser considerado na relação com o outro, e propõe-se a conceptualização da identidade cultural. Esse deslocamento conceptual faz com que seja necessário pontuar algumas considerações acerca do conceito de identidade, pensado como "identificação", que sugere uma construção, um processo sempre em devir, não especificamente em relação ao sujeito, mas em relação à (construção de) identidade(s). Talvez justamente por isso um dos livros mais conhecidos de Stuart Hall não tenha por título "O sujeito cultural na pós-modernidade", mas A identidade cultural na pós-modernidade. Para isso, Hall vai discorrer acerca da concepção de identidade que remonta ao Iluminismo, quando esta era vista como algo fixo e imutável, visando distanciar-se de tal conceptualização. No Iluminismo, segundo Hall (2001), o sujeito era visto como centrado, dotado de capacidades como razão, consciência e ação. O "centro" consistia num núcleo interior que emergia quando o sujeito nascia e com ele se desenvolvia permanecendo o mesmo, idêntico a si ao longo de sua existência. Por isso, considerava-se que "o centro essencial do eu era a identidade de uma pessoa" (HALL, 2001, p. 11) Essa mudança se alterou no decorrer do século XX, devido a transformações ocorridas, principalmente, por causa da globalização. Não sendo mais o sujeito considerado uno e idêntico a si, a identidade passa a ser pensada como múltipla, movente e heterogênea.

É importante mencionar que as (re) leituras do conceito de identidade foram e continuam sendo operadas em inúmeros âmbitos. Segundo Stuart Hall (2001), Kathryn Woodward (2000) e Tomaz Tadeu da Silva (2003), a identidade não é autorreferencial, 
mas relacional, só se desenvolve na relação com o outro. Isso porque "só afirmamos quem somos, a que grupo pertencemos (nação, região, sexo) quando existe um não nós e um outro que faz parte de nós" (SANTOS, 2011, p. 145). Santos (2011) menciona que o conceito de identidade é um dos mais férteis para pensar fenômenos socioculturais da contemporaneidade. Há, segundo o autor, uma necessidade constante de atualização, problematização e instauração de reflexões que permitam fundamentar interpretações no entorno desse fenômeno. Tanto que, no âmbito dos Estudos Culturais, ele chega a mencionar a adoção da expressão "processos de identificação/diferenciação" ao invés da utilização do termo identidades. Exemplificando, o autor vai mencionar que "só há sentido em afirmar a nacionalidade brasileira, por exemplo, frente a um não brasileiro, caso contrário essa afirmação seria desprovida de sentido" (SANTOS, 2011, p. 145). Para ele, identidade e diferença são indissociáveis; logo, sem a diferença não existe identidade. Por isso, vai falar em processos de identificação/diferenciação.

No escopo da $\mathrm{AD}$, ainda, outra explicação é possível: os processos identitários são contingenciais porque as identidades se transformam em razão das contingências. Quem o afirma é Grigoletto (2006), que volta sua atenção para a transitoriedade e indeterminação dos processos de identificação. Ela vai afirmar que "todas as identidades, entendidas como resultados provisórios de práticas identitárias, existem apenas como estratégias, no sentido que podem ser sempre reformuladas, daí a sua contingência e indeterminação" (GRIGOLETTO, 2006, p. 24).

É importante mencionar que quando se diz que as identidades culturais não são móveis ou fixas, isso não significa que não haja identificações que busquem estabilizações, ainda que provisórias. Se, por um lado, a identidade não pode ser pensada somente como uma "festa móvel” (cf. HALL, 2001) também não pode ser vista como uma essência imutável, conforme assinala José Manuel Oliveira Mendes (2005). Por isso, Santos (2011) vai ser ainda mais específico: para ele as identidades culturais se fazem em meio a processos dialéticos de fixação-mudança porque muitos aparatos são mantidos ao cabo que outros são transformados. Trata-se de um processo de mudança-permanência em que pode haver maior evidenciação, no decorrer do tempo, de um processo sobre o outro, ainda que ambos continuem existindo nas instâncias de construção de identidades.

Isso nos permite afirmar que a identidade só adquire sentido se relacionada ao 
outro, ao que está noutro lugar e nos discursos sociais em que é produzida, assim como mostra sua indissociável relação com a historicidade. Do exposto, fica evidenciado que tanto a $\mathrm{AD}$ quanto os Estudos Culturais compreendem a identidade como uma construção discursiva, constitutiva na historicidade, o que permite e favorece a interface entre a AD e os Estudos Culturais. No que se refere, ainda, à identidade, é salutar destacar que na sociedade atual, contemporânea, não há mais a compreensão de uma identidade rígida, unificada, homogeneamente orientada, pois se entende que as identidades estão em sempre em movimento, são cambiantes.

Nessa compreensão, torna-se fundamental frisar que não há identidade sem sujeito, assim como também não há sujeito sem discurso. Logo, tanto a $\mathrm{AD}$ quanto os Estudos Culturais dialogam na compreensão de um sujeito não individualizado, empírico, mas um sujeito clivado, múltiplo, disperso, de semelhante modo às suas identidades. A hipótese principal, por meio da articulação entre AD e os Estudos Culturais, então, é que o discurso tende a legitimar identidades. Assim, pensando na intersecção com os Estudos Culturais, a identidade pode ser pensada como um processo cultural, construída nos discursos sociais que circulam na sociedade.

\section{ANÁLISE DO CORPUS DISCURSIVO}

A partir da posição teórica e analítica da $\mathrm{AD}$, tomada na interface com os Estudos Culturais, foram selecionadas 3 (três) charges. O critério de escolha foi selecionar materialidades que apresentassem discursos identitários acerca do sujeito professor. Nesse contexto, vale destacar que o professor, enquanto sujeito que ocupa determinada função social, é percebido com frequência como alguém sobre o qual recai a necessidade de redirecionamento de práticas sociais diferentes de práticas tradicionais exercidas no passado, visando atender às demandas do mundo moderno, às transformações do mundo do trabalho e o avanço do alcance das novas tecnologias dentro e fora de sala de aula. Contudo, conforme se pode observar nas próximas três charges, há uma percepção que se apresenta através do descrédito relacionado à figura docente, tomada como lugar profissional desfavorecido, principalmente no que diz respeito à desvalorização financeira do profissional. Basta observar como o professor é apresentado na sequência seguinte: 
Charge 1: Dia 15 de outubro

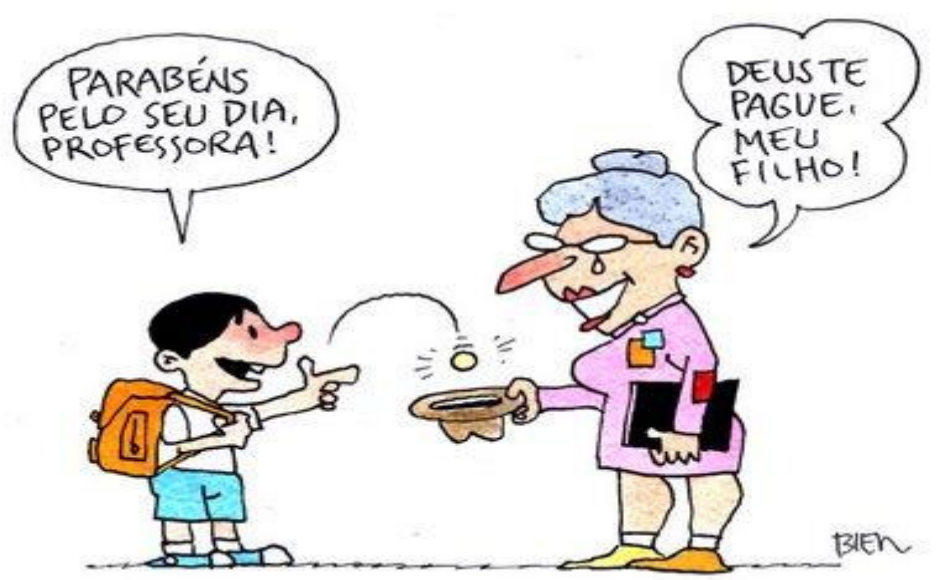

Fonte: <https://br.pinterest.com/pin/811914639046771351/>. Acesso em: 1 jun. 2020.

Charge 2: Professora e faxineira

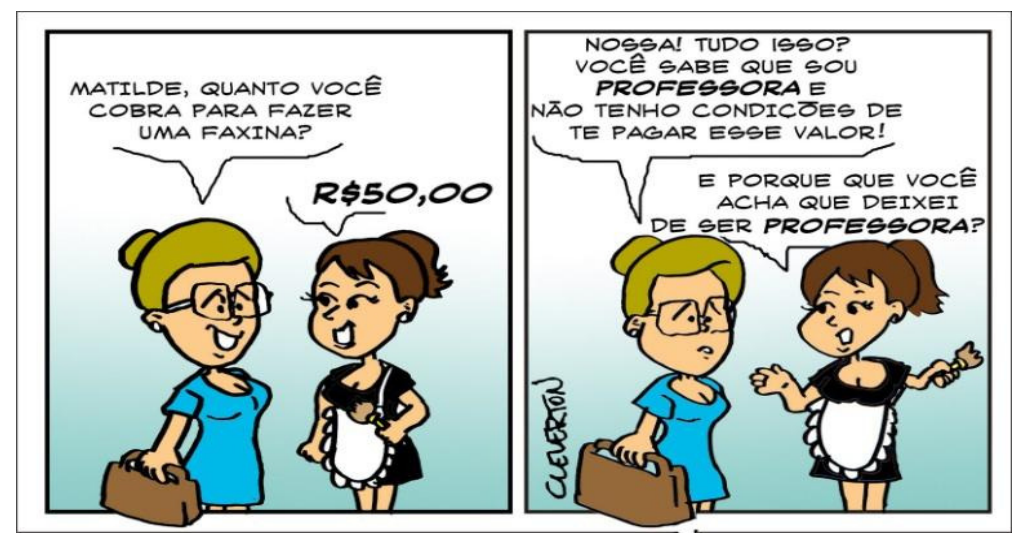

Fonte: $<$ https://br.pinterest.com/pin/529665606145554113/?send=true $>$. Acesso em: 1 jun. 2020.

Charge 3: O professor e o assaltante

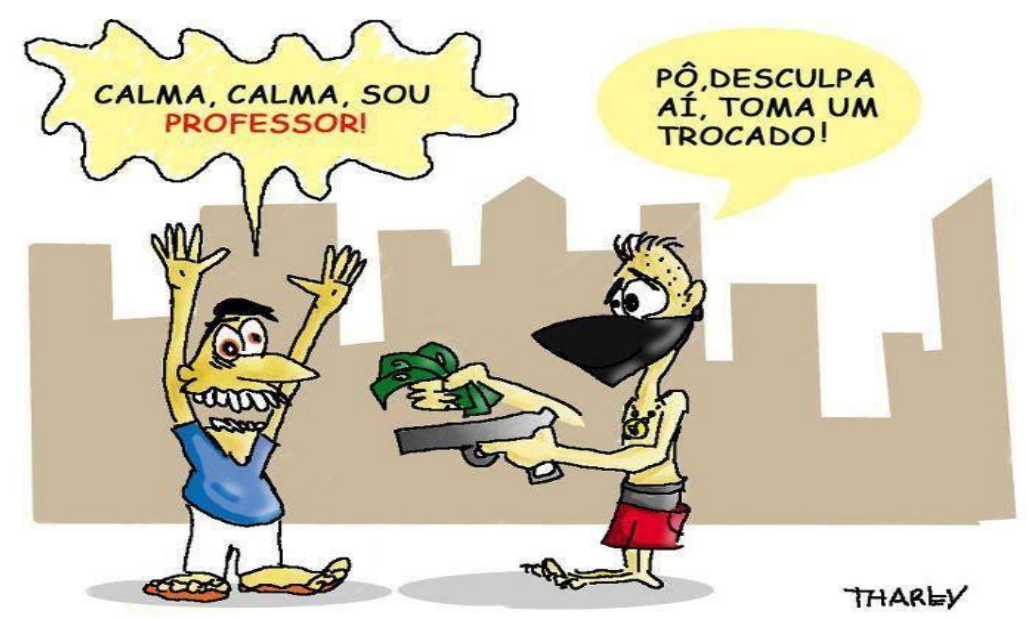

Fonte: $<$ https://www.pinterest.co.uk/pin/415527503090064967/>. Acesso em: 1 jun. 2020. 
Ao observar essas três charges, é preciso invocar Pêcheux (1969), para destacar a compreensão de que o sujeito na $\mathrm{AD}$ é visto como resultado da relação com a linguagem e a história e, também, que o sujeito do discurso não é totalmente livre nem totalmente determinado por mecanismos exteriores (cf. LEANDRO FERREIRA, 2001). Nesse viés, pode-se falar em posição-sujeito ou também em função. Nesse caso, vale destacar que "a posição-sujeito não é uma realidade física, mas um objeto imaginário, representando, nos processos discursivos, os lugares ocupados pelos sujeitos na estrutura de uma formação social” (LEANDRO FERREIRA, 2001, p. 21). Por isso, observamos a posição-sujeito de professor e como esta função significa na historicidade.

Como se pode observar nas três charges, a posição-sujeito de professor nos é apresentada num discurso de forma a provocar efeito de sentidos negativos. Como bem definiu Pêcheux (1990, p. 82): "discurso é o efeito de sentido entre locutores”. Na charge 1, temos, como condições de produção do discurso, uma professora segurando um chapéu no interior do qual a moeda de um aluno está sendo jogada. Na charge 2, temos uma professora que se encontra diante de uma situação calamitosa por não poder pagar a faxina de cinquenta reais a uma empregada doméstica e, na charge 3, temos um assaltante que desiste do assalto ao saber, sobre o assaltado, que se trata de um sujeito que exerce a função social de professor. Isto é, temos, nas três charges, efeito de sentidos negativos relacionados à posição-sujeito de professor, referência a instâncias relacionadas à formação de sua identidade docente.

Conforme já apresentado no aporte teórico, para Silva (2003), a identidade se constitui pela diferença, sendo esta, pois, a condição de existência daquela. Ao afirmar "sou brasileiro" estou dizendo também "não sou europeu" e ao afirmar que sou nordestino, gaúcho, mineiro, também há um efeito de diferenciação em relação ao que não sou e assim por diante. $\mathrm{O}$ autor acrescenta que as identidades não existem espontaneamente no mundo cultural, mas a identidade e a diferença são produtos sociais, "fabricados" pela /na linguagem. De acordo com ele:

A identidade e a diferença não podem ser compreendidas, pois, fora dos sistemas de significação nos quais adquirem sentido. Não são seres da natureza, mas da cultura e dos sistemas simbólicos que a compõem. [...] Somos nós que as fabricamos no contexto de relações culturais e sociais. (SILVA, 2003, p. 76-78). 
Por tal motivo, percebe-se nas três charges que a circulação da identidade do professor é constituída nas condições de produção que favorecem a diferença entre as identidades. Isto é, na charge 1 , a posição sujeito de professor nos é apresentada numa relação social com um sujeito-aluno, na charge 2, com um sujeito que ocupa a posição social de empregada doméstica e, na charge 3, com o sujeito-assaltante, ladrão. Contudo, nas três charges analisadas, o sujeito-professor aparece sempre ocupando uma posição inferiorizada: aquele que precisa de uma ajuda financeira, aquele que não tem dinheiro para pagar suas despesas e aquele que não tem nada para ser assaltado.

Assim, as três formas de representação da identidade docente nas charges analisadas ecoam o efeito de descrédito da figura do professor na sociedade contemporânea $^{3}$, de sua identidade associada ao âmbito profissional que se articula com uma instância intrínseca ao fazer-se docente, sugerindo uma crise atual em relação à constituição da identidade docente, se formos considerar os pressupostos de Bauman acerca da identidade (2001). Assim, a constituição dessas charges favorece uma apresentação da posição-sujeito de professor que demonstra um efeito de humilhação, respaldado culturalmente em uma teia de relações valorativas acerca do fazer e, ainda mais, associadas à remuneração escassa deste profissional.

É interessante perceber o importante papel da memória discursiva presente como elemento constitutivo nestas três charges. Na charge 1, a memória discursiva aciona, também, saberes que não estão explícitos na charge, contudo por meio de indícios linguísticos, presentes no diálogo entre a professora e o aluno, no efeito de gratidão da professora, ao dizer: Deus te pague, meu filho! Somado a isso pode ser mencionada a construção do discurso não verbal em que a professora está sendo representada como uma velhinha com chapéu de mendigo em uma das mãos. $\mathrm{O}$ ato de jogar a moeda que o aluno faz ao parabenizá-la pelo seu dia também é significativo: produz-se assim o efeito de que o salário dos professores é insuficiente permite a equiparação com corpos desviantes que estão nas ruas pedindo esmolas após saírem ou durante o trajeto de seu trabalho (a professora está vestida de modo a apresentar elementos associados à sala de aula - como

\footnotetext{
${ }^{3}$ É importante mencionar que, no âmbito da $\mathrm{AD}$, o enunciador não é "dono" do discurso, então seria destoante mencionar que as charges promovem o efeito de descrédito sobre a figura do professor. Isso porque, considerando que o "enunciador" não é fonte ou origem dos enunciados, em termos de interdiscurso, seu intradiscurso apenas refrata já-ditos.
} 
adesivos e pasta -, pode estar indo ou voltando da escola, neste caso).

Desse modo, discurso verbal e não verbal ativam a memória discursiva acerca do sucateamento da profissão docente e, mais que isso, ativam a memória social sobre o fato de que tal desvalorização não ocorre somente em tempos recentes: a figura da professora é representada por uma velhinha, não por uma moça jovem, e o ato de segurar um chapéu onde recolhe a moeda que o aluno lhe joga reforçam o efeito de desassistência governamental.

Outro elemento não verbal chama atenção na construção da cena discursiva da charge: o discente é uma criança, ainda não iniciada no mundo do trabalho, e está de certo modo oferecendo uma moeda, símbolo daquilo que falta à professora, já que, ao receber, ela o agradece. Temos, também, através desta cena, o esboço de assinalamento da desigualdade social onde estudantes, oriundos de famílias abastadas ou com pais que não trabalham como professores estão melhores assistidos financeiramente que os próprios docentes. Neste caso, pode ser mencionado o que o Pêcheux (1969) abordou como sendo alguma coisa que fala, antes, noutro lugar independentemente e diferentemente, pois, temse ressoado algo que é dito noutro lugar, situado na exterioridade, que se reinscreve através da memória, pois tal efeito é cristalizado na sociedade como usual de um sujeito que fala a partir da posição social de pedinte de esmolas, que ao ser atendido, responde: Deus te pague! Todavia, esse discurso do pedinte é ressignificado, atualizado, levando-se em consideração que não se trata, agora, de um diálogo entre um mendigo e um abastado, mas de um sujeito-aluno e um sujeito-professor, que passa a ocupar a posição social de menos favorecido, necessitando das moedas de um aluno.

Tal situação nos remete a Orlandi (2005) ao salientar que as condições de produção compreendem fundamentalmente os sujeitos e a situação. Também a memória faz parte da produção do discurso. E é justamente a inscrição na história que faz com que o sentido possa ser outro. A maneira como a memória é acionada faz valer as condições de produção, tornando-se fundamental. Assim, na charge 2, a memória discursiva aponta para a exterioridade, para o que é dito noutro lugar, presente na historicidade acerca da posiçãosujeito de empregada doméstica, tida pela sociedade brasileira como uma das posições sociais de menor poder aquisitivo, pois as formações imaginárias marcam este lugar, esta posição-sujeito de empregada doméstica, entretanto, nesta relação de identidades sociais, 
quem se apresenta na charge 1 como a posição social de menor poder aquisitivo é a posição-sujeito de professor, que produz um efeito de espanto ao expor que não tem condições de pagar uma faxina por cinquenta reais, justamente porque fala a partir da posição-sujeito de professor.

Culturalmente determinadas, profissionais são pensadas como sendo associadas a classes sociais menos favorecidas. É o caso das empregadas domésticas, cuja memória discursiva associa-as a um lugar desprivilegiado financeiramente. O uso de uma ironia, que é comum em textos chargísticos é operado através de uma inversão de papeis: isso porque, na vida em sociedade, aquela que pergunta sobre o valor cobrado pela faxina o faz por interesses de contratação. Mas, na prática, o segundo quadrinho inverte as funções de mais privilegiada e menos privilegiada, já que a que está em vias de prestação de serviços domésticos recebe mais do que aquela que indaga sobre as condições financeiras de contratação.

A ridicularização da docência, operada sobre um elemento de identificação financeiro - ativa discursivamente a memória social acerca da desassistência monetária da profissão. A última frase da empregada, que remete a um passado e um presente profissional, reforça tal ironia já que 50 reais é apresentado como um valor acima das condições de remuneração docente. Desse modo, a identificação com uma característica associada à identidade docente não permite aquela que é representada como sujeito docente uma condição financeira suficiente para pagar esse valor, isso mostrado sob o efeito de sentido de ironia, de ridicularização da posição-sujeito de professor.

Também o discurso não verbal contém elementos que promovem uma separação entre o novo e o velho, sobre algo que está na ordem da imanência, da estabilização e algo que está na ordem da transformação: a professora é representada como uma senhora velha de óculos e coque no cabelo, cuja memória representa uma simbolização de algo que estagnou, assim como o salário dos professores. Já a empregada doméstica é representada como uma moça jovem cujo cabelo, apesar de amarrado, está representado num corte mais moderno, solto nas pontas, o que pode remeter a um efeito de inscrição num passado como professora que foi ressignificado através da mudança de profissão.

Se a linguagem é histórica e social, ela também se modifica com o tempo, alterando-se de acordo com sujeitos e grupos sociais que a empregam. Assim também são 
as formas de identificação e desidentificação que constituem o bojo da construção identitária dos sujeitos. O coque feminino, assim como os sujeitos, desliza entre o velho e o efeito de novidade, ao mesmo tempo em que reforça estereótipos em relação ao lugar da mulher na sociedade.

Se os sentidos não são evidentes assim como a linguagem não é transparente houve uma pornografalização de gestos femininos na representação da mulher se levarmos em consideração a primeira charge em relação à segunda. $\mathrm{O}$ decote à mostra não é apenas acessório, diz respeito a uma constituição de familiaridade sobre modos de representação do feminino na sociedade. Lemos (2000) destaca a imagem que a mídia faz da mulher, "pornografando-lhe" os gestos e neutralizando seu sexo. O que as edições pornográficas fazem é "uma paródia da feminilidade tal como os homens a imaginam em seus fantasmas". A mulher frequentemente é percebida como objeto de desejo, associada ao desejo, e, nas palavras de Lemos (2000), considerando os estudos de Baudrillard (2000), supersimulam-lhe a feminilidade. Dessa forma, ainda que a ideia central seja a representação do sujeito professor, recai discursivamente sobre a charge o gesto de interpretação que desnaturaliza modos de pensar o feminino na sociedade o que, também, diz respeito à formação cultural da identidade.

Nesse direcionamento, na charge 3, o papel da memória discursiva também é constitutivo na produção do discurso. Assim, como bem já salienta Pêcheux ao apontar que:

[...] a memória discursiva seria aquilo que, face a um texto que surge como acontecimento a ser lido, vem restabelecer os 'implícitos' (quer dizer, mais tecnicamente, os pré-construídos, elementos citados e relatados, discursos-transversos, etc.) de que sua leitura necessita: a condição do legível em relação ao próprio legível (PÊCHEUX, 1999, p.52).

Logo, ao apresentar um sujeito mascarado com uma arma em punho, a memória discursiva revela os "implícitos", dialogando com a exterioridade, acerca da posiçãosujeito de ladrão, assaltante. É importante frisar que é a ideologia materializada neste discurso quem produz o efeito de evidência que naturaliza a compreensão de que um sujeito de máscara e arma em punho apontando pra outro sujeito, é um assaltante. Mas a charge 3 traz uma distinção que parece acessória, mas pode ser fundamental para entender 
modos de representação social acerca da docência: trata-se de um homem, desta vez, que está na rua, mas que, diferente da senhora que aparece nas charges anteriores, não traz na representação não verbal elementos físicos que poderiam remeter à profissão. Inclusive se forem extraídas as falas da charge não restam elementos que no discurso não verbal assegurem que se trata de um professor.

Parece acessório, mas as formas como feminino e masculino são representadas nas charges destoam. Então não podemos falar apenas de identificações ou desidentificações em relação ao fazer docente. Há práticas e representações também associadas ao gênero. Homens e mulheres são construídos de modo diferente e o homem goza de maior liberdade mesmo em relação a formas de ser representado profissionalmente. Não é à toa que o homem sobre quem recai a ação do assalto não realizado está de chinelos, de camiseta, sem óculos ou qualquer indício que aponte para uma instância de constituição profissional. Por que é importante mencionar isso? Porque há formas diferentes de pensar e representar homens e mulheres que implicam no movimento de considerar a hierarquização social e cultural existente na sociedade.

Vale destacar que onde quer que haja diferença há sujeitos em desnível em relação uns aos outros. No mercado de trabalho isso não é diferente. Mendes e Milani (2016), por exemplo, analisaram desigualdades situadas a partir de um recorte de gênero na sociedade brasileira centrando o debate na inserção de mulheres no mercado de trabalho. Para isso se utilizaram de informações extraídas dos censos de 1980, 1991, 2000 e 2010. Conclui-se, respaldando-se no estudo mencionado, que, mesmo mediante nível de escolaridade similar entre sujeitos, há desigualdade entre homens e mulheres, por exemplo. Isso porque quando há uma diferença que situa sujeitos separando-os, mesmo que as condições de formação sejam idênticas, então podemos falar que há uma distinção sendo operada. No caso das charges, até mesmo na rua mulheres foram representadas com indícios que apontam para a profissão e, ao homem, só a fala do balão de diálogo aponta para sua inscrição profissional em condições específicas de exercício. É como se fosse ativada a memória de que há uma desigualdade entre homens e mulheres no mundo do trabalho, onde mulheres precisam trabalhar o dobro para serem reconhecidas. Há, então, formas singulares de discursivização e subjetivação acerca de modos de ser homem e ser mulher na sociedade, mesmo que ambos ocupem o mesmo lugar profissional. 
Isso posto, para Pêcheux (1999) todo discurso se constitui a partir de uma memória e do esquecimento de outro. Assim, a memória é o saber discursivo, o já-dito, os sentidos a que já não temos mais acesso, que foram constituídos ao longo de uma história e que estão em nós, sem pedir licença. Desse modo, percebe-se que, nas três charges apresentadas, há esquecimentos, silenciamentos, pois ao se mostrar, em sua identidade docente, a posição-sujeito professor como: "o coitadinho", "o que precisa ser ajudado", "o carente", não se mostra a posição-sujeito professor com um efeito de valoração social positiva, não se mostra como aquele que capacita a todos os outros sujeitos sociais em suas posições profissionais, por exemplo.

Mesmo na charge 2 quando um dos sujeitos é apresentado como não sendo mais vítima da situação de desfavorecimento financeiro relegada aos professores ainda assim é apresentada uma mulher, como faxineira, numa posição que aponta para a estereotipação feminina. Ao sair da docência, preservou-se, discursivamente, na charge 2, o lugar de falta de privilégios ainda que seja uma falta privilegiada em relação a posição de sujeito docente, ocupada anteriormente. Tais valores passam a ser esquecidos, silenciados muitas vezes na leitura das charges e o que se aflora é a identidade docente marginalizada, pois aparece sempre à margem das outras posições-sujeitos: o aluno, a empregada doméstica (ex-professora) e o assaltante.

Do exposto, pode-se observar como compreendem Pêcheux e Fuchs (1990) um acionamento de memórias que, entre outros diálogos e observações, apontam para uma sintonia entre exercer a posição-sujeito de professor e não ter dinheiro, que chega ao ápice da desmoralização social, do descrédito na figura docente, de uma identidade desvalorizada, por meio de vestígios linguísticos e não verbais, que dialogam com a exterioridade, quando, por exemplo, o assaltante chega a pedir desculpas ao professor pelo assalto: -"Pô, desculpa, aí, toma um trocado". Neste caso, há um duplo efeito de ironia: primeiro porque o assaltante, que o imaginário social produz como sendo da ordem da necessidade, tem menos necessidade financeira que o professor. Segundo que o mito de que o exercício de uso da norma padrão equivaleria a uma ascensão social também é ironizado já que o professor, que cursou uma licenciatura, adentrando os meandros de formação universitária, não teve retribuição financeira equivalente aos seus esforços de formação em relação a alguém com formação instrucional escolar insuficiente. 
Vale salientar que tal frase é dita mostrando o ladrão com o dinheiro numa mão, para dar ao professor e com a arma na outra mão. $\mathrm{O}$ uso da palavra trocado que remete a troco, algo que supostamente sobraria, que constitui um restante de dinheiro satiriza ainda mais a condição do professor já que o resto do dinheiro de alguém desassistido governamentalmente, como o assaltante, é maior do que o que sobra do salário do professor. Assim, nas três charges, considerando o contexto de relações de poder, o sujeito-professor protagonista tem aparição passivamente, numa relação de poder que o coloca hierarquicamente inferiorizado em relação ao outro. Assim, o sujeito-aluno oferece ao sujeito-professor o que há de menor valor no dinheiro, uma moeda, que faz com que a professora se emocione, com lágrimas nos olhos, produzindo um efeito de gratidão e de necessidade. No caso do assaltante a reação de oferecer dinheiro se dá mediante a apresentação de um enunciado que revela a condição profissional do homem que seria assaltado, desfavorecido financeiramente em relação ao próprio assaltante, que tem mais "trocados" que o outro.

No que se refere à identidade, para o sociólogo Bauman (2005, p. 96), "nosso mundo fluido exige que as identidades não sejam permanentes”. Essa é uma condição da vida moderna. Logo, a identidade é sempre plural. Somos, segundo o teórico em pauta, consumidores de identidades. Desse modo, pode-se afirmar, por exemplo, que a empregada doméstica passou da posição-sujeito de professor para a posição-sujeito de empregada doméstica justamente por não conseguir honrar suas dívidas na função docente. Assim, produz-se, nas três charges, um efeito de evidência de ser professor e não ter dinheiro ainda que, mesmo no âmbito da formação da identidade docente, as formas de identificação e desidentificação de ser homem e ser mulher destoem, por exemplo, mostrando que a identidade não pode ser vista como um parâmetro homogeneizador de sujeitos. Ressalta-se, ainda que nas três charges a posição-sujeito de professor é mostrada identificada à posição-sujeito que atribui aos docentes a posição de coitadinhos, de menos favorecidos já que nelas os próprios sujeitos assumem tal posição de identificação ao dizerem: "Deus te pague, meu filho", Calma, calma, sou professor" e "Nossa, tudo isso? Você sabe que sou professora". 


\section{REVISTA $\mathbf{X}$}

\section{EFEITO DE FECHAMENTO}

Por meio das análises realizadas acerca do discurso, do sujeito-professor, da memória e da identidade pode ser mencionado que a relação entre sujeito, discurso e identidade é constitutiva, pois a identidade está atrelada a um sujeito e os sujeitos são constituídos discursivamente. Desse modo, foi possível compreender que os sentidos produzidos através das charges ecoam um efeito de estabilizar, fixar e normatizar a identidade do sujeito-professor, por meio de símbolos que são repetidos social e culturalmente em um universo de práticas e representações associado a uma rede de memórias que o tempo todo é retomada e ressignificada nas charges analisadas.

Nesse jogo de representações há sempre relações de poder atravessando os corpos e a identidade docente representada está sempre sujeita aos valores atribuídos a ela por quem a representa. Assim, os gestos de análise efetuados sobre as charges apontaram para o estabelecimento de um efeito de descrédito e de crise da identidade docente atual.

\section{REFERÊNCIAS}

ALMEIDA, J. F. de. Para uma epistemologia da errância: erro, hiância e ciência em Michel Pêcheux. Tese (Doutorado em Ciência, Tecnologia e Sociedade) - Centro de Educação e Ciências Humanas, Universidade Federal de São Carlos, São Carlos, 2018.

AZAMBUJA, D. Teoria geral do Estado. São Paulo: Globo, 1998.

BAUDRILLARD, J. Da sedução. Campinas: Papirus, 2000.

BAUMAN, Z. Identidade. Rio de Janeiro: Zahar, 2005.

. Modernidade líquida. Trad. Plínio Dentzien. Rio de Janeiro: Jorge Zahar, 2001.

COSTA, L. C.; SILVEIRA, É. L. Efeito Bolsonaro: anatomia do autoritarismo. In: SILVEIRA, É. L. (Org.). Os efeitos do autoritarismo: práticas, silenciamentos e resistência (im) possíveis. São Paulo: Pimenta Cultural, 2018, v. 1, p. 13-35.

COURTINE, J. J.; HAROCHE, C. (1988). O homem perscrutado: semiologia e antropologia política da expressão e da fisionomia do século XVII ao século XIX. In: LANE, S. M. T. (Org.). Sujeito e texto. São Paulo: EDUSC, 1994, p. 37-60.

GRIGOLETTO, M. Leituras sobre a identidade: contingência, negativação e invenção. In: MAGAlHÃES, I.; CORACINI, M. J.; GRIGOLETTO, M. (Orgs.). Práticas identitárias: 
língua e discurso. São Carlos: Claraluz, 2006, p. 15-44.

HALL, S. A identidade cultural na pós-modernidade. 5. ed., Rio de Janeiro: DP\&A, 2001.

A centralidade da cultura: notas sobre as revoluções culturais do nosso tempo. Educação \& Realidade, v. 22, n. 2, p. 15-46, jul./dez. 1997.

Quem precisa de identidade? In: SILVA, T. T. da (Org.). Identidade $e$ Diferença: a perspectiva dos Estudos Culturais. Petrópolis: Vozes, 2000, p. 103-133.

LEANDRO FERREIRA, M. C. (Org.). Glossário de termos do discurso. Porto Alegre: Instituto de Letras da UFRGS, 2001.

LEMOS, A. Arte eletrônica e cibercultura. In: MARTINS, F. M.; SILVA, J. M. da (org.) Para navegar no século XXI: tecnologias do imaginário e cibercultura. 2.ed. Porto Alegre: EDIPUCRS, Sulina, 2000.

MARIANI, B. O comunismo imaginário, práticas discursivas da imprensa sobre o PCB (1922-1989). Tese (Doutorado em Linguística) - Instituto de Estudos da Linguagem, Universidade Estadual de Campinas, Campinas, 1996.

MENDES, A. A. E.; MILANI, M. L. Inserção da mulher negra brasileira no mercado de trabalho no período de 1980-2010. Revista Latino-americana de Geografia e Gênero, v. 7, n. 2, p. 178-194, ago/dez., 2016.

MENDES, J. M. O. O desafio das identidades. In: SANTOS, B. S. S. (Org.). A Globalização e as Ciências Sociais. São Paulo: Cortez, 2005, p. 503-540.

ORLANDI. E. P. Discurso e texto: formação e circulação dos sentidos. Campinas: Pontes, 2001.

. As formas do silêncio: no movimento dos sentidos. Campinas: UNICAMP, 2007.

. Análise do Discurso: princípios \& procedimentos. São Paulo: Pontes, 2005.

PÊCHEUX, M. (1969). Análise automática do discurso. In: GADET, F.; HAK, T. Por uma análise automática do discurso: uma introdução à obra de Michel Pêcheux. Campinas: Ed. da Unicamp, 1990, p. 61-161.

. Papel da memória. In: ACHARD, P. et al. (Org.). Papel da memória. Tradução e introdução de José Horta Nunes. Campinas: Pontes, 1999, p. 49-57.

. Rôle de la mémoire, Langage et Société, p. 261-267, 1983.

. Semântica e discurso: uma crítica à afirmação do óbvio. Trad. de Eni Puccinelli Orlandi, Lourenço Chacon Jurado Filho, Manoel Luiz Gonçalves Corrêa e Silvana Mabel Serrani. Campinas: editora da Unicamp, 1988. 
PÊCHEUX, M.; FUCHS, C. A propósito da análise automática do discurso: atualização e perspectivas (1975). In: GADET, F.; HACK, T. (Orgs). Por uma análise automática do discurso: uma introdução à obra de Michel Pêcheux. Campinas: Unicamp, 1990, p. 163252.

PIOVESAN, Â. M. W.; FORLIN, C. M.; MOHR, D.; MARTINEZ, J. Z.; MONTEIRO, S. L.; FRANCO, Z. A análise do discurso e questões sobre a linguagem. Revista X, v. 2, p. 1$18,2006$.

SANTOS, L. dos. As identidades culturais: proposições conceituais e teóricas. Revista Rascunhos Culturais, v. 2, jul./dez. 2011, p. 141-157.

SILVA, S. B.; FATIMA, W. S.; SILVEIRA, É. L. (Para não esquecer que) a luta de classes é o motor da história: notas sobre Pêcheux e o materialismo histórico. REVISTA PHILOLOGUS, v. 26, p. 306-313, 2020.

SILVA, T. T. da (org.). Identidade e Diferença: a perspectiva dos estudos culturais. 2.ed. Petrópolis: Vozes, 2003.

SILVEIRA, É. L.; DUARTE, Á. M. S. O discurso e as (des) identificações: reflexões acerca do feminismo e as vozes de resistência na atualidade. Rascunhos Culturais, v. 3, p. 143-163, 2012.

TORRES, C. A. Democracia, educação e multiculturalismo. Dilemas da cidadania em um mundo globalizado. Petrópolis: Vozes, 2001.

WOODWARD, K. Identidade e diferença: uma introdução teórica e conceitual. In: SILVA, T. T. (org.). Identidade e Diferença: a perspectiva dos estudos culturais. 2.ed. Petrópolis: Vozes, 2000, p. 7-72.

Recebido em: 01 jun. 2020.

Aceito em: 24 ago. 2020. 